\title{
A teoria da aprendizagem experiencial como alicerce de estudos sobre desenvolvimento profissional ${ }^{1}$
}

\author{
Alessandra Pimentel \\ Universidade Federal do Rio Grande do Norte
}

\begin{abstract}
Resumo
A teoria da aprendizagem experiencial consiste em uma abordagem sobre o desenvolvimento do adulto, em especial, do profissional. Segundo seu fundador, o americano David Kolb, a profissionalidade é um percurso permanente de aprendizagem, desde que o indivíduo possa se apropriar de suas experiências de atuação profissional. São discutidos os princípios e conceitos básicos dessa perspectiva, fundamentados na relação entre determinados tipos de aprendizagem, denominados modalidades de aprendizagem, e o desenvolvimento dos processos afetivos, perceptivos, cognitivos e comportamentais, presentes ao longo do percurso profissional ou em situações específicas de aprendizagem, como é o caso de projetos de formação em serviço. A perspectiva holística e integrativa da aprendizagem experiencial se aproxima das tendências contemporâneas que destacam o papel do pensamento reflexivo para melhoria da qualificação profissional. Contudo, a acepção kolbiana segue um caminho próprio, original, com grande potencial de aplicação para estudos e propostas formativas no campo do desenvolvimento profissional.
\end{abstract}

Palavras-chave: aprendizagem experiencial; david kolb; desenvolvimento profissional; aprendizagem do adulto

\begin{abstract}
The experiential learning theory as the basis for the research about professional development. The theory of the experiential learning consists of a perspective about the development of the adult, in special, of the professional. According to its founder, the American David Kolb, the profissionality is a permanent process of learning, provided the individual can assume appropriate the experiences of professional performance. The principles and basic concepts of this approach are presented, based on the relation between certain types of learning and the development of the affectivity, perception, cognition and behavior belonging to the professional life track or in specific situations as it is the case of projects of formation in service. The holistic and integrative perspective of the experiential learning has some proximity with contemporary approaches which emphasize the role of the reflective thought for improvement of the professional qualification. However, Kolb's theory follows a proper and original way, with great potential for studies and formative proposals for the professional development.
\end{abstract}

Keywords: experiential learning; david kolb; professional development; adult learning

A melhoria da qualificação profissional tornou-se, desde os anos 90, tema vinculado à noção de desenvolvimento profissional, numa vertente de pensamento contrária às visões de capacitação e aperfeiçoamento, largamente difundidas nas décadas antecedentes. Preconiza-se que a formação profissional não cessa nunca; implica na contínua aquisição de conhecimentos, atitudes e competências ao longo da carreira. Pressupõe-se que o desenvolvimento profissional decorre do engajamento pleno do profissional em seu próprio processo de aprendizagem. Em decorrência, compreender mais profundamente o desenvolvimento do profissional é fundamental para a formulação de programas de formação e propostas de análise da atuação profissional.
O conceito de desenvolvimento da profissionalidade reflete a qualificação quanto a competências, conhecimentos, sentimentos e postura ética relativos à profissão. Nessa perspectiva, a teoria da aprendizagem experiencial - formulada por David Kolb (1984) ${ }^{2}$ - atribui grande valor aos conhecimentos de caráter experiencial, cuja utilidade para engendrar desenvolvimento só existe na medida em que podem ser confrontados, comparados, ampliados, revisados, enfim, refletidos junto a conhecimentos de caráter teórico. "Portanto, há que integrar conhecimento estruturado e conhecimento experiencial para construir um percurso de desenvolvimento profissional" (Oliveira-Formosinho, 2002, p.146).

O intuito desse artigo é, sobretudo, divulgar a aprendizagem 
experiencial a pesquisadores e profissionais interessados no tema do desenvolvimento profissional, salientando-se o fato de ainda serem inéditas edições em português da obra de Kolb.

\section{Conceitos fundamentais da aprendizagem experiencial}

A aprendizagem experiencial parte da seguinte premissa: todo desenvolvimento profissional prospectivo decorre da aprendizagem atual, assim como o desenvolvimento já constituído é imprescindível para o aprendizado.

Aprender pela experiência não significa que qualquer vivência redunda em aprendizagem. Esta aprendizagem é, sobretudo, mental. Assim sendo, apropriar (tornar próprios) os saberes procedentes da experiência demanda processos contínuos de ação e reflexão.

De acordo com a perspectiva de Kolb, o homem é um ser integrado ao meio natural e cultural, capaz de aprender a partir de sua experiência; mais precisamente, da reflexão consciente sobre a mesma. Uma pessoa aprende motivada por seus próprios propósitos, isto é, empenha-se deliberadamente na obtenção de aprendizado que lhe faça sentido. Nas palavras do autor, aprendizagem experiencial é:

o processo por onde o conhecimento é criado através da transformação da experiência. Esta definição enfatiza... que o conhecimento é um processo de transformação, sendo continuamente criado e recriado... A aprendizagem transforma a experiência tanto no seu caráter objetivo como no subjetivo... Para compreendermos aprendizagem, é necessário compreendermos a natureza do desenvolvimento, e vice-versa (1984, p. 38)

Nesse sentido, a aprendizagem não se efetua apenas no plano cognitivo. Na reflexão consciente sobre as experiências, a fim de transformá-las em aprendizagens, é igualmente decisivo considerar os sentimentos, emoções e intuições (Alarcão, 2002) que compõem o funcionamento psicológico, numa estrutura holística composta de cognição, afetos, percepção e ação.

A teoria kolbiana tem no postulado histórico-cultural (Vygotsky e seguidores) uma fonte de inspiração ${ }^{3}$. Com vistas à qualificação da profissionalidade, Kolb afirma que a gênese do desenvolvimento profissional encontra-se no processo de aprendizagem, aludindo a princípios e conceitos vygotskianos, mormente os de zona de desenvolvimento proximal, mediação, internalização, generalização e descontextualização. "Aprendizagem é o processo por onde o desenvolvimento ocorre" (Kolb, 1984, p. 132). Segundo este ponto de vista, à semelhança do que enuncia a abordagem histórico-cultural, aprendizagem resulta da ação humana sobre o ambiente. Conforme o ser humano se torna capaz de atribuir significado a suas experiências, revendo-as e planejando o futuro, dialeticamente o ambiente e ele próprio se transformam mútua e reciprocamente, ambos são simbólica e concretamente metamorfoseados.

A aprendizagem experiencial enfatiza a interdependência entre características internas do ser aprendente e circunstâncias externas do ambiente, entre conhecimento de origem pessoal e social. A aprendizagem é individual na medida em que toda ação educativa é uma libertação de forças, tendências e impulsos existentes no indivíduo, elementos volitivos de direção e de orientação da atividade. Em contrapartida, vida social e educação se prolongam reciprocamente. Toda educação é social, conquista de um modo de agir comum. Nada se ensina nem se aprende, senão através de uma compreensão comum ou de um uso comum. O conhecimento é social, "não existe somente em livros, fórmulas matemáticas ou sistemas filosóficos; requer aprendizagem interativa para interpretar e elaborar estes símbolos" (Kolb, 1984, p. 122). "O processo de aprendizagem advindo da experiência determina e atualiza o desenvolvimento potencial. Esta aprendizagem é um processo social; portanto, o curso de desenvolvimento individual é determinado pelo sistema cultural e social de conhecimento" (Kolb, 1984, p. 133).

Kolb sustenta esse postulado no conceito de zona de desenvolvimento proximal de Vygotsky, interpretando-a como um princípio metafórico, representativo da multiplicidade de dispositivos culturais, dirigidos à promoção de desenvolvimento. Não se trata de um lugar específico, mas de um regime de práticas que engendram a apropriação, pelos sujeitos, de um sistema particular de regras integrantes do convívio e das exigências sociais. "Através de experiências de imitação e de comunicação com outras pessoas e de interação com o ambiente físico, as potencialidades de desenvolvimento são estimuladas e postas em prática até que internalizadas como desenvolvimento efetivo [real] independente" (Kolb, 1984, p. 133).

$\mathrm{Na}$ visão de Kolb, a experiência é central para o desenvolvimento. Faz parte de um processo dialético e ininterrupto de aprendizagem, presente permanentemente ao longo da vida do indivíduo. As experiências de aprendizagem levam ao desenvolvimento porque se dirigem a uma meta, um propósito específico de aprendizado.

Em termos de princípios educacionais, a conceituação kolbiana de aprendizagem e desenvolvimento pretende diferenciar-se

de teorias racionalistas e outras teorias cognitivistas que tendem a dar ênfase primordial à aquisição, manipulação e uso de símbolos abstratos, e de teorias comportamentais de aprendizado que negam qualquer papel à consciência e à experiência subjetiva no processo de aprendizado. Deve-se enfatizar, no entanto, que o objetivo deste trabalho [é] sugerir, através da aprendizagem experiencial, uma perspectiva holística, integrativa, que combina experiência, percepção, cognição e comportamento. (Kolb, 1984, p. 20-21)

\section{Características fundamentais da aprendiza- gem experiencial}

\section{Avalia-se aprendizagem pelos processos, não pelos produtos}

As idéias não são elementos fixos e imutáveis de pensamento, estão sempre se formando e reformulando por meio da experiência; mais precisamente, dos sentidos dados à experiência. O confronto de idéias é inexorável à elaboração de significados. A partir desse processo dinâmico, são arquitetados 
conhecimentos cada vez mais sofisticados. Conhecimentos consolidados se aprofundam, generalizam e se tornam mais complexos por intermédio da elaboração de outros, novos, ainda não acabados, mas já capazes de transformar o saber pré-existente.

Conhecer é um processo de contínua invenção e recriação hipotética sobre a realidade. $\mathrm{Na}$ elaboração de uma hipótese, tornamos explícitos elementos inteligíveis de nossa experiência. Pensamos sobre, recorrendo a idéias e conceitos conhecidos e formulando outros.

Formular hipóteses é engendrar modos de agir que nos fazem capazes de articular o que conhecemos em função dos propósitos de uma situação experiencial em particular, seja ela total ou parcialmente nova. Numa experiência de aprendizagem, unimos e selecionamos informações, aprimoramos procedimentos, separamos e elegemos elementos que a compõem, ordenamos esses elementos em seqüências distintas, adicionamos novos. Há, portanto, diversas operações de pensamento antes mesmo de testarmos as hipóteses que, inicialmente amórficas e nebulosas, são revistas, reelaboradas e aprimoradas, até se tornarem sólidas o suficiente para se generalizarem, servindo de referência a experiências futuras. Mas levantar hipóteses de princípios não implica somente em habilidade de expressá-los simbolicamente, isto é, expor com palavras. Antes, requer capacidade de observar conexões entre ações e seus efeitos, numa escala ordenada de eventos, fatos e circunstâncias.

A generalização tem capital importância na criação de hipóteses. Generalizar demanda extrair saberes, a partir de uma circunstância particular, que sejam expansivos, ampliando o cabedal de princípios teóricos e/ou metodológicos. Hipóteses generalizáveis são conjecturas capazes de antever situações análogas à vivenciada e conceber previamente como atuar nelas.

\section{O desenvolvimento é unilinear e multilinear}

Kolb se posiciona contrário às abordagens historicamente marcadas pelo acento na dimensão cognitiva e rejeita a perspectiva unilinear de desenvolvimento. Para ele, o maior problema do cognitivismo é delegar à cognição o papel de superestrutura, como se ela governasse todo o comportamento, convertendo o desenvolvimento em um curso linear e progressivo. De seu ponto de vista, a cognição não progride separadamente das outras dimensões de desenvolvimento, visto que a inteligência humana nasce de conflitos e diálogo entre cognição, afetividade, percepção e ação. Sua perspectiva transacional de desenvolvimento é concebida como produto da interação entre diferentes tipos de conhecimento.

Na aprendizagem experiencial, essa interação é responsável pelo desenvolvimento contínuo, processual e multilinear do adulto. Kolb considera que a cultura na qual um grupo está inserido é, para o mesmo, um campo universal de conhecimentos socialmente produzidos, base para seus membros compartilharem posições, percepções, julgamentos, crenças, mitos e ideologias tão universais quanto os domínios de conhecimento existentes. Pode-se dizer, então, que este universal relativo segue os parâmetros ditados por aquele campo social específico.
A aprendizagem experiencial coloca a ênfase na interação entre o sujeito e a ação e sustenta as novas aprendizagens na experiência, ao mesmo tempo em que valoriza o contexto e a reflexão. Mas, ao valorizar também o lado funcional da aprendizagem, sua exteriorização social, adquire uma dimensão pragmática que... é essencial [não apenas] porque promove a resolução de problemas pelos atores envolvidos, mas também por conceder a estes o poder de os resolver e a consciência de que detêm esse poder. (Alarcão, 2002, p. 230)

É pela espiral entre ação e reflexão que o homem transforma a si e o seu entorno sócio-cultural. Este processo dialético requer confronto e resolução dos conflitos inerentes à situação de aprendizagem experienciada, do que resulta "o progressivo desenvolvimento humano, por crescente diferenciação $e$ hierarquização integrativa [grifos nossos] do funcionamento psíquico" (Kolb, 1984, p. 134) - conceitos a serem discutidos mais adiante.

\section{Aprender é um processo contínuo e ascendente, im- pulsionado pela experiência}

$\mathrm{Na}$ acepção de Kolb, o desenvolvimento é representado por três níveis sucessivos - aquisitivo, especializado e integrativo - correspondentes a três esferas qualitativamente distintas de consciência, conforme a complexidade das ações e dos processos reflexivos de cada ser singular, em cada momento de seu desenvolvimento.

A transição entre os níveis é variável, pois depende da apropriação das experiências culturais que cada pessoa em particular vivencia. Devido às oscilações de um nível a outro, não se pode estimar ou classificar os profissionais segundo um único modo de aprender. Por exemplo: um piloto de avião que não dirige automóvel terá um nível integrado de consciência quanto às operações aprendidas para pilotar aeronaves; em contrapartida, terá um nível aquisitivo para dirigir um fusca. Contudo, somente ao dar início ao aprendizado automobilístico, tornar-se-á explícita e factível a maneira como o nível integrativo para pilotar auxilia no novo empreendimento. Por ora, vejamos cada um desses níveis isoladamente.

Nivel aquisitivo de desenvolvimento (consciência identificadora). Nesta etapa, ao se deparar com um conhecimento novo, o desenvolvimento do profissional é performático, voltado para a ação. Por sua vez, a consciência é identificadora (registrative consciousness), busca identificar, reconhecer e registrar objetos envolvidos na ação.

O nível aquisitivo se caracteriza por aprendizado de habilidades básicas que estão na base das estruturas cognitivas responsáveis pela simbolização. Simbolizar consiste no registro consciente de experiências reais, numa representação independente da concretude com que foram vivenciadas. A consciência identifica e distingue realidade concreta de realidade virtual (idealizada e fantasiosa). Os produtos desse desenvolvimento são a lógica representacional e o processo racional de construção de hipóteses e deduções. "Estas capacidades permitem imaginar ou hipotetizar implicações dentro de um sistema puramente simbólico e de testá-los na realidade, convergindo em aprendizagem pela transformação 
de uma dada compreensão por extensão [grifos nossos] a outros setores de conhecimento" (Kolb, 1984, p. 142).

O desenvolvimento na fase de aquisição é marcado pela emergência gradual da consciência sobre a própria identidade, que inclui tanto o âmbito pessoal quanto o profissional.

Nivel especializado de desenvolvimento (consciência interpretativa). No nível de especialização, o foco não está mais na performance, mas nos significados atribuídos à ação. A consciência se torna interpretativa. Embora, no nível aquisitivo, já exista interpretação para atribuir significados às ações, a ênfase está no registro do que é necessário à performance. Falta organizar aquelas interpretações em redes de significação, exatamente o que caracteriza o desenvolvimento em nível especializado.

A especialização incrementa a adaptação à atuação profissional. É consagrada uma relevância que outrora não existia a todas as escolhas pessoais referentes à identidade profissional. "O mais poderoso e dinâmico desenvolvimento que emerge desta interação entre as escolhas é a tendência de tornar cada vez mais forte o vínculo entre características pessoais e demandas ambientais" (Kolb, 1984, p. 143). Esta correspondência é mutuamente transformadora, enquanto o ambiente social modifica as características pessoais, cada indivíduo elege para si, e valoriza, somente os dispositivos sociais que atendem a suas necessidades e características pessoais. Nesse processo de definição da individualidade estável, a autoconsciência é governada, sobretudo, por parâmetros de conteúdos: coisas que posso fazer, experiências que já tive, defeitos e qualidades que possuo.

Nivel integrado de desenvolvimento (consciência integrativa). Para Kolb, a consciência estruturalmente integrada deve-se à reunião de diferentes ações, operações e significações num nível holístico. O integrativo é o estágio mais complexo do desenvolvimento, manifesto tanto pela segurança e autoafirmação decorrentes da capacidade de reconhecer as próprias competências quanto pela necessidade de novas mudanças, em aspectos que a pessoa julga importante alterar, aprimorar, transformar ou destituir.

É, seguramente, um nível de confrontação existencial. O profissional dirige a atenção para si. Avalia-se, torna-se objeto de investigação. Tal condição pode se desencadear lentamente ou ser precipitada por uma experiência com forte carga afetivo-emocional, como a perda do emprego ou uma promoção repentina. Algumas pessoas, dependendo do quão imersas estão num determinado enquadre social, podem nunca chegar ao nível integrativo. Num sistema hermético ou cristalizado, sem pressão para contínua avaliação da atuação, cabe praticamente ao indivíduo o esforço de conquistar esse patamar de desenvolvimento profissional.

Do nível aquisitivo ao integrativo, aspira-se sempre a constituição de estruturas complexas de consciência; mas vale acrescentar que "cada estágio do desenvolvimento maturacional é caracterizado pela conquista de um nível estrutural de consciência superior ao do estágio precedente, embora se mantenham reminiscências dos primeiros níveis de consciência" (Kolb, 1984, p. 146).

A atribuição de significados à experiência, bem como a atenção especial a seus elementos constitutivos (idéias, saberes, modos de pensar, etc.) se conformam ao nível das estruturas de consciência durante a experiência de aprendizagem. Nas palavras de Kolb (1984): “[as] estruturas de consciência governam o processo de aprendizagem estabelecido pela experiência, por meio da seleção e definição do que se experiencia” (p. 146)

Em termos de desenvolvimento de diferenciação e integração,
os processos elementares de aprendizagem são os meios
primários de diferenciação da experiência; as combinações
dessas formas elementares numa ordem superior representam
a pressão integrativa do processo de aprendizagem. O foco
consciente da experiência, que é selecionado e formado pelo
nível pessoal de desenvolvimento real, é refinado e diferenciado
na zona de desenvolvimento proximal, apropriando-se dela e a
transformando. (Kolb, 1984, p. 146)

Tendo em conta a caracterização dos três níveis de consciência, é razoável considerar que uma mesma experiência possa engendrar aprendizados de diferentes graus de complexidade. As mudanças de maior magnitude, em nível integrativo, resultam do gerenciamento de processos cognitivos baseado na reorganização e generalização conceitual de elementos não totalmente inéditos, conhecidos por intermédio de experiências de aprendizagem anteriores. Outros elementos, embora desconhecidos, devido à semelhança com saberes e operações mentais já constituídos, são tratados com alguma familiaridade, num nível especializado. Finalmente, modos de atuar na realidade e conhecimentos completamente novos são apreendidos no nível aquisitivo.

$\mathrm{Na}$ realidade, é comum a confluência dos três níveis de consciência na mesma experiência. Há, sem dúvida, vários fatores intervenientes, como os requisitos necessários para vivenciá-la, o potencial de desenvolvimento do profissional, o envolvimento afetivo com a situação e as condições de aprendizagem, sem nos esquecermos da história singular de aprendizagens vividas e saberes formulados por cada indivíduo concreto, determinando a maneira como os níveis de consciência se organizam e entrelaçam. A consciência, numa dada experiência de aprendizagem, não é hegemônica, assim como uma pessoa não tem desenvolvimento homogêneo, nem em nível real, nem em potencial. Para reforçar essa idéia, Kolb se reporta à zona de desenvolvimento proximal, conceito vygotskiano que sublinha a dialética entre desenvolvimento real e potencial. A cada nova situação de aprendizagem há múltiplas zonas de desenvolvimento em processo e, de igual modo, há níveis distintos de consciência. Nessas múltiplas zonas incorrem quatro modos ou modalidades de aprender pela experiência, discutidas a seguir.

\section{Modalidades de aprendizagem}

No sistema explicativo de Kolb, toda aprendizagem implica na existência/constituição de estruturas mentais subjacentes à apropriação e elaboração dos conhecimentos advindos da experiência. Trata-se, portanto, de um modelo explicativo estrutural. Mas o funcionamento dessas estruturas é igualmente imprescindível, pois a forma com que essas estruturas estão organizadas e inter-relacionadas define os diferentes estilos de 
aprendizagem, havendo um sistema estrutural correspondente a cada estilo.

Ao longo da história, podemos encontrar diferentes autores que refletem sobre o papel da experiência na aprendizagem. Dentre as concepções erigidas, encontramos a defesa acirrada e dicotômica, ora do papel da teoria ora da prática. Numa visão integradora da teoria com a prática, o americano David Kolb (1984) apresenta sua perspectiva... que designou de aprendizagem experiencial, assentada na articulação em duas dimensões opostas: a dimensão do concreto/abstrato e do ativo/ reflexivo... No bojo de sua conceituação, Kolb resolve a tensão entre estas dimensões por meio de duas operações mentais: preensão da experiência e sua transformação. A aprendizagem experiencial consiste, desse modo, na compreensão e na transformação da experiência. (Finger, 1989, citado por Alarcão, 2002, p. 226)

Da relação entre aprender, conhecer e desenvolver, o ciclo de aprendizagem experiencial integra quatro modelos adaptativos de aprendizagem, pelos quais preensão e transformação se conjugam. A seguir, são explicitadas as características de cada um desses modelos.

Experiência concreta (EC). Refere-se a experiências de contato direto com situações que propõem dilemas a resolver. As ações são referenciadas em conhecimentos e processos mentais já existentes, aprendidos anteriormente. Principalmente por atitudes de experimentação, obtém-se a matéria-prima para aprendizagens ulteriores.

Observação reflexiva (OR). Constitui-se num movimento voltado para o interior, de reflexão. Caracteriza-se por atitudes, sobretudo, de pesquisa sobre a realidade, como: identificação de elementos; construção de associações; agrupamentos entre os fatos perceptíveis da experiência; determinação de características, dificuldades e possibilidades de escolhas; partilha de opiniões sobre um determinado assunto.

Conceituação abstrata (CA). Caracteriza-se pela formação de conceitos abstratos e generalizáveis sobre elementos e características da experiência. Constitui-se de ações de comparação com realidades semelhantes, bem como generalização de regras e princípios, cujo intuito é estabelecer sínteses a partir da troca de opiniões, estabelecendo-se um tronco comum de idéias compartilhadas.

Experiência ativa (EA). É a repercussão das aprendizagens em experiências inéditas, num movimento voltado para o externo, de ação. Caracteriza-se por aplicação prática dos conhecimentos e processos de pensamento tornados refletidos, explicados e generalizados. A ação está centrada em relações interpessoais, com destaque à colaboração e ao trabalho em equipe.

Aos pares (por exemplo, EC e CA), esses modelos se traduzem em novas dimensões, através das quais aprendizagem pode engendrar desenvolvimento. Essas dimensões representam as duas posições dialéticas do aprendizado: preensão e transformação. Enquanto a preensão conjuga o concreto ao abstrato, a transformação conjuga a ação à reflexão. Por sua vez, os elementos internos das duas dimensões também se articulam mutuamente. Vejamos como se caracterizam essas dimensões, para, mais adiante, discutir as combinações entre elas.

(1) A relação dialética entre concreto e abstrato se manifesta na aprendizagem por preensão, através da combinação entre experiência concreta e conceituação abstrata. A aprendizagem por preensão implica dois processos opostos (apreensão e compreensão), pelos quais a pessoa pode se reportar à experiência e relatá-la.

(1.1) Apreensão: tangível pela experiência imediata, ou seja, por aprendizagem diretamente vinculada à experiência concreta, de natureza mais intuitiva e instantânea, derivada, sobretudo, de percepção, exemplificação e imitação. Para Kolb, o ato de apreender é circunscrito por atenção, valoração e afirmação, configurando-se uma apreciação da experiência.

(1.2) Compreensão: reflete interpretações conceituais e representações simbólicas, isto é, a aprendizagem é orientada pela conceituação abstrata, cuja natureza distanciada da experiência imediata e reflexiva permite a formação de imagens mentais. Compreender os significados da experiência envolve "um processo dialético integrando experiência e conceitos, observações e ação" (Kolb, 1984, p. 22), configurando uma análise objetiva e crítica da experiência.

Apreensão apreciativa e compreensão crítica são igualmente fundamentais na (re)construção e produção dos conhecimentos e, portanto, fundamentam o desenvolvimento complexo e integrado.

(2) A relação dialética entre reflexivo e ativo se manifesta na aprendizagem por transformação, através da combinação entre observação reflexiva e experiência ativa. Na transformação, os processos opostos (intenção e extensão) alicerçam a representação simbólica da experiência para a pessoa (re)significar seu próprio potencial de aprendizagem.

(2.1) Intenção (interiorização psíquica): reflexão intencional, consciente e determinada por processos mentais de autoavaliação. $\mathrm{O}$ aprendizado não apenas se transforma como é transformador das operações mentais. A intenção é um ato consciente e voluntário, cujo caráter metacognitivo determina mudanças na estrutura e no funcionamento psicológico.

(2.2) Extensão (exteriorização social): ação no mundo exterior, em interação com outras pessoas. $\mathrm{O}$ aprendizado se dá pela extensão de determinadas ações para novas experiências. A noção de extensão simboliza ampliar um ato ou efeito, torná-lo duradouro. Assim sendo, a extensão é pragmática por excelência, haja vista que somente o retorno à experimentação coloca à prova o que se apreciou, observou, hipotetizou e conceituou anteriormente.

Da mesma forma que a articulação entre apreender e compreender é essencial à elaboração de conhecimentos concretos e abstratos, os processos de transformação (operações mentais para refletir e agir) são mutuamente complementares e imprescindíveis para o desenvolvimento psicológico. A Figura 


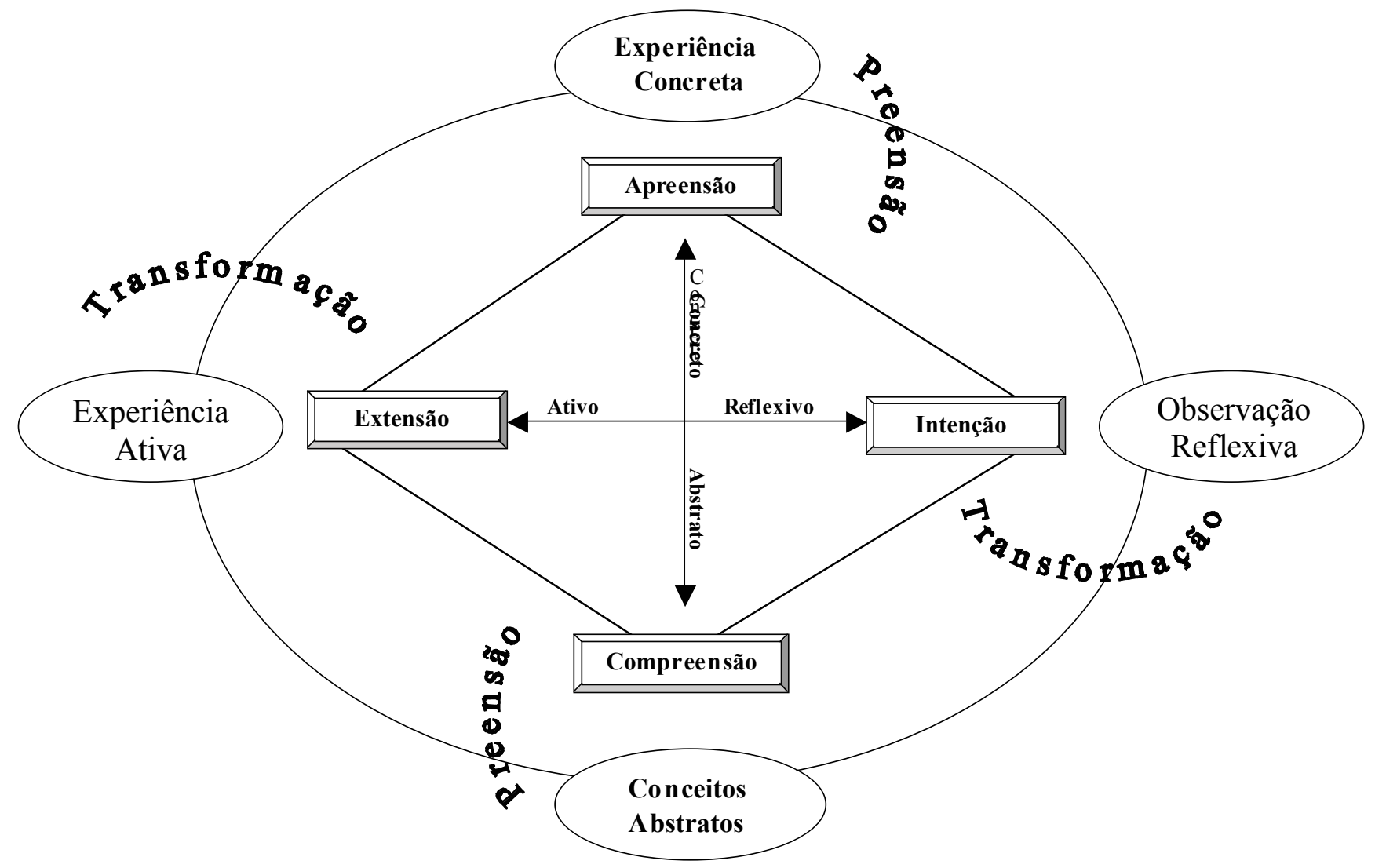

Figura 1. Ciclo de aprendizagem experiencial ${ }^{4}$

1 retrata o modelo de aprendizagem experiencial, ressaltando o movimento dialético e cíclico entre os quatro modelos de aprendizagem.

A Figura 1 representa o ciclo de aprendizagem experiencial. Do centro para fora, as setas entrecruzadas indicam as duas dimensões que unem ação prática e teorização; nas molduras retangulares identifica-se as quatro facetas do desenvolvimento; as inscrições côncava/convexa e verticalizadas referem-se aos sistemas de pensamento; e, por fim, nas molduras ovaladas estão indicadas as quatro modalidades de aprendizagem.

Na proposição de Kolb, experiência concreta, observação e reflexão, formação de conceitos abstratos e, finalmente, teste de hipóteses e conceitos em situações novas constituem os pilares do vínculo cíclico e dialético entre experiência vivida, construção de conhecimento e projeção de aprendizagem em experiências futuras.

Esse ciclo quadrifásico de aprendizagem experiencial pode iniciar a partir de quaisquer das modalidades, resultando em formas distintas de intervir na realidade e aprender com a experiência. Supondo-se o início pela experiência concreta, segue-se a observação sobre as condições da experiência, sua meta e as ações erigidas. Nessa etapa, o exemplo advindo da experiência imediata é compreendido, propiciando o exame e a seleção de ações que possam ser aplicadas a circunstâncias semelhantes, a fim de antecipar novas experiências e projetar ações plausíveis. Em seguida, o foco se dirige à descoberta de princípios gerais, são erigidas hipóteses explicativas, não apenas cabíveis ao exemplo particular, mas de caráter mais conclusivo, úteis para novas situações de aprendizagem. Finalmente, os conhecimentos e desenvolvimento resultantes podem ser testados, na experiência ativa, a partir da qual o ciclo se renova de modo ascendente e contínuo.

Os conceitos de experiência concreta, observação reflexiva, conceituação abstrata e experiência ativa, isolados, não fazem sentido algum. Por isso, Kolb elabora combinações entre eles, tendo em conta as dimensões de preensão e transformação. A combinação é sempre constituída pela união entre um dos processos de preensão (apreensão e compreensão) e um dos de transformação (extensão e intenção), resultando em quatro combinações denominadas elementares, devido à associação ocorrer entre dois componentes ${ }^{5}$. Vamos a elas.

Preensão (EC) transformada por extensão (EA). Essa relação implica em apreender a experiência concreta (EC) balizando-se na experiência ativa (EA). Por meio da projeção de experiências futuras transcorrem mudanças na apreciação perceptual da experiência atual, em sua apreensão. Essa apreensão não é conceitual, é apreciativa. O foco está nos julgamentos, atitudes e valores pessoais que de algum modo emergem daquelas projeções.

Ao atentarmos para as sensações deflagradas por vivências envolventes, instigantes ou mesmo, de frustração, tornamo-nos mais cônscios do que nos agrada, do que nos causa repulsa, incômodo e do que pretendemos experienciar com mais freqüência. Estão em jogo as características observáveis da 
situação concreta. A apreensão antecede a ação, influenciando no planejamento e criação de hipóteses a partir das observações palpáveis ditadas pela concretude da experiência.

Compreensão (CA) transformada por extensão (EA). Esta combinação também é formada por experiência ativa (EA) que, agora, alicerça a conceituação abstrata (CA). O caráter prospectivo se mantém, como na combinação anterior.

Compreender significa tanto construir conceitos quanto ser capaz de torná-los extensivos (extensão) a outros casos. Contudo, por causa da combinação da conceituação com a experiência ativa, a atuação avaliada se baliza num modelo abstrato, teórico, a fim de se predizer metas de ação. A extensão prepondera sobre a compreensão, modificando e reorganizando os conceitos necessários para extrair conhecimentos a partir de experiências de aprendizagem que, na verdade, ainda não se concretizaram, embora sejam totalmente factíveis.

Apreensão (EC) transformada por intenção (OR). Essa estratégia de aprendizagem deriva do vínculo entre experiência concreta (EC) e observação reflexiva (OR). A intenção exerce um papel menos óbvio que a extensão (ou exteriorização) por se orientar para o sujeito aprendente, atuando no plano intrapessoal. A intenção requer esforços próprios, através de processos metacognitivos de auto-avaliação.

A observação reflexiva coordena a apropriação da experiência. Trata-se de refletir, de forma autocrítica, para deduzir conhecimentos da experiência. Deduzir é um meio de transformar a maneira de refletir sobre nossas experiências, modificando as observações feitas em princípio, rearranjando elementos e atributos, abandonando um ponto de vista para considerar outro; antes, ignorado.

Compreensão (CA) transformada por intenção (OR). As modalidades envolvidas são conceituação abstrata (CA) e observação reflexiva (OR). Enquanto a formulação de conceitos via extensão é sobejamente pragmática, testando-se hipóteses na experiência ativa; as mudanças conceituais via intenção são inferidas. $\mathrm{Na}$ inferência, explicitamente reflexiva, recorremos à indução, observando partes específicas da experiência para chegar a leis ou conceitos gerais, partindo das conseqüências para chegar aos princípios, dos efeitos para as causas. A intenção precede a inferência. Em outras palavras, a reflexão intencional orienta a compreensão para que os conhecimentos sejam aprofundados, ganhem abstração e generalidade.

As combinações foram didaticamente discutidas em separado. Não nos alongamos no detalhamento, nem explicitamos outras combinações, cabíveis a quaisquer dos exemplos dados. Entretanto, seria incorreto supor que, por exemplo, o preparo para uma nova atividade profissional se respalda somente em compreender conceitos, com vistas a externá-los posteriormente (compreensão por extensão). A pessoa inteira está envolvida na atividade. Seu comportamento em geral, estado afetivo, envolvimento com os propósitos da tarefa, percepções, ponderações dedutivas e indutivas estão todos articulados no ato de aprender.

Certamente, são diversos os arranjos possíveis, em função da ênfase numa ou noutra combinação, bem como na associação entre combinações. Kolb denomina tais arranjos de estilos de aprendizagem. É indiscutível que a história pessoal, particular, de aprendizados - dentro e fora do campo profissional - exerce grande influência na definição desses estilos. É fato, também, que uma mesma pessoa utilizará combinações diferentes em situações distintas de aprendizagem. Portanto, não é nada simples firmar tipologias de estilos de aprendizagem. Aliás, tentativas de qualificar ou classificar estilos pessoais nos parece ingênuo, dada a complexidade inerente ao processo de aprender.

\section{Integração e diferenciação}

Na teoria kolbiana, integração e diferenciação são conceitos imprescindíveis para compreender a relação entre aprendizagem e desenvolvimento. Até agora, foram caracterizadas as modalidades de aprendizagem, sem se especificar como conhecimentos aprendidos são integrados e diferenciados dos conhecimentos já consolidados no desenvolvimento da pessoa. É fato que as modalidades de aprendizagem, ou melhor, combinações entre elas, estão presentes em qualquer nível do desenvolvimento profissional. No entanto, ser capaz de combinar as modalidades de acordo com cada situação específica de aprendizagem experiencial é crucial para o profissional tomar decisões e estar consciente de seu próprio processo de desenvolvimento, possibilitando reconhecer suas competências e identificar o que precisa melhorar.

Aprender se respalda num determinado desenvolvimento anterior e, paradoxalmente, fundamenta o potencial de desenvolvimento ulterior. Mas, afinal, o que isso significa? Primeiro, significa que aprender e desenvolver é imanente ao ser humano em todas as dimensões da vida e que ambos constituem uma relação contínua e interdependente. Por outro lado, significa que são transitórios, baseiam-se em conhecimentos e modos de atuar que, internalizados, potencializam o surgimento de novos saberes. A dialética entre aprendizagem e desenvolvimento evoca conhecimentos inéditos e novos meios de solucionar problemas.

Para explicar esse fenômeno, Kolb elabora os conceitos de integração hierárquica (hierarchic integration) e diferenciação crescente (increasing differentiation).

A diferenciação se dá em dois sentidos simultâneos: (a) aumento da complexidade do conhecimento, para constituir um todo, uma unidade; e (b) interdependência entre suas partes. No curso da relação entre aprendizagem e desenvolvimento, a diferenciação é responsável pelo refinamento de conhecimentos e modos de atuar. A integração é constituída por uma escala hierarquizada, com níveis múltiplos, ordenando elementos e atributos em categorias.

O primeiro nível dessa escala integrativa corresponde a regras simples e inflexíveis, com as quais são organizadas as diferentes dimensões da experiência num sentido único e absoluto. Por exemplo, classificar as experiências como boas ou más.

Num dado momento da aprendizagem, emerge uma regra alternativa que também passa a reger a interpretação das situações. A noção imperiosa certo-errado se flexibiliza por intermédio de pensamentos contingenciais. Coexistem duas formas de interpretação: a do nível anterior e a alternativa. Paulatinamente, o absolutismo e a inflexibilidade são substituídos 
pela relatividade e flexibilidade.

No nível seguinte, são desenvolvidas regras mais complexas que as do pensamento contingencial, proporcionando uma visão em perspectiva. Essas regras são mais livres da aplicação baseada apenas na experiência passada ou em estímulos externos.

O mais alto nível de integração adiciona um outro sistema de regras, formando uma estrutura de generalidades (intersecção entre generalizações), que implica em interações mais sofisticadas entre as regras. Essa estrutura propicia grande flexibilidade de integração e diferenciação, resultando na capacidade de lidar com mudanças e incertezas ambientais por meio de desenvolvimento de construções alternativas complexas acerca da realidade.

Estes quatro níveis hierárquicos estão diretamente associados à capacidade pessoal de encontrar relações alternativas, criar novas perspectivas, cujas regras sejam cada vez mais flexíveis para dar conta de uma gama maior de situações que venham a ser experienciadas. Em outras palavras, correspondem a graus crescentes em complexidade no desenvolvimento profissional, observada pela melhoria na escolha entre as combinações de modalidades de aprendizagem, em função das condições e tipos de experiência em que o profissional se engaja.

$\mathrm{Na}$ medida em que ascende na hierarquia, o indivíduo formula conhecimentos melhor caracterizados e especificados. A integração funciona como um esquema modular, cujo propósito é organizar e controlar o processamento de subordinações e diferenciações dos conceitos, sentimentos, atos e observações.

$\mathrm{O}$ desenvolvimento se consolida à medida que a integração se torna complexa e a diferenciação se amplia. Esses dois processos se entrecruzam, no sentido de constituírem um único eixo, mediante quatro dimensões: complexidade afetiva, complexidade perceptiva, complexidade simbólica e complexidade comportamental.

A complexidade alcançada nessas dimensões enseja, paralelamente, maior sofisticação das modalidades de aprendizagem a elas arraigadas. Por conseguinte, as modalidades estipulam mudanças internas em direção a novos níveis de desenvolvimento. Essa dialética enaltece o fato de que nem as dimensões nem as modalidades se tornam mais complexas, independentemente uma da outra. Articulam-se "num processo holístico de aprendizagem” (Kolb, 1984, p. 139).

Kolb enfatiza que os níveis de complexidade são múltiplos e variáveis tanto quanto são os conhecimentos do mundo e os acessos de cada ser humano para se envolver em experiências com tais conhecimentos.

O desenvolvimento... prossegue de um estado de embevecimento, defesa, dependência e reatividade para o estado de autorealização, independência, pró-atividade e significações que o próprio sujeito dá. Este processo é marcado pelo aumento em complexidade e relativismo [grifos nossos] no modo de compreender o mundo, a si mesmo e as próprias experiências no/com o mundo, e por integrações em níveis superiores do conflito dialético entre as quatro modalidades preliminares de aprendizagem. (Kolb, 1984, p. 140)

No início do desenvolvimento, o progresso de cada uma dessas quatro dimensões pode ocorrer com relativa independência das demais. Pode haver, por exemplo, um domínio muito mais sofisticado de proficiência simbólica em comparação ao campo afetivo. "O desenvolvimento num modo precipita desenvolvimento nos outros" (Kolb, 1984, p. 140) à medida que se sucedem experiências de aprendizagem e de exercício de criatividade, exigindo um ciclo superior de integração. A Tabela 1 apresenta uma síntese da teoria da aprendizagem experiencial.

\section{À guisa de síntese}

Segundo Kolb, aprendizagem implica um processo reflexivo pelo qual a profissionalidade se desenvolve. $\mathrm{O}$ autor alerta que a reflexão impõe considerar dois processos básicos: perceber e processar, vinculados respectivamente às dimensões concreta/ abstrata e ativa/reflexiva. Tais dimensões constituem a base de sustentação de um ciclo de aprendizagem, envolvendo: experiência concreta, observação reflexiva, conceituação abstrata e experimentação ativa.

A experimentação é vital para se estabelecer relações entre prática e teoria, visando promover o desenvolvimento profissional. Com a experiência concreta, idéias, valores, crenças e histórico pessoal de aprendizado são peças de um mesmo tabuleiro, em que apreender novos conceitos e maneiras de reorientá-los principia um processo ascendente e dialético de aprendizagem.

A observação reflexiva é a investigação sobre a experiência vivida, em que fazemos uso de processos mentais de dedução hipotética, num movimento voltado para o interior, metacognitivo (denominado por Kolb de intencional ou de intenção). Em contrapartida, é necessário encontrar as respostas e solucionar as hipóteses, o que nos leva ao terceiro movimento, de conceituação abstrata. Na conceituação, estão envolvidos planejamento sistemático, uso da lógica e desenvolvimento de princípios teóricos, visando compreender e resolver problemas. Para conceituar, generalizamos, extraímos conclusões que permitem não apenas compreender a experiência precedente, mas alcançar novo nível de experimentação.

À luz das análises metacognitivas e interpretações abstratas, as hipóteses são testadas num movimento para o exterior (extensional ou de extensão). A experimentação ativa é a resultante de reorientações da ação, em que "aprender é examinar as hipóteses, experimentando-as, incorporando-as ou modificando-as em função das novas situações de experiência" (Kolb, 1984, p. 26). Pela ação no real, examinam-se os conceitos formulados e apropriam-se aqueles que efetivamente são capazes de sustentar a prática.

É mediante esse ciclo de modalidades, central na perspectiva da aprendizagem experiencial, que o profissional extrai de suas próprias experiências aprendizagens significativas para seu desenvolvimento, em níveis crescentes de diferenciação e integração de conhecimentos, habilidades e competências.

Pretendemos nesse artigo expor os princípios e conceitos da abordagem kolbiana no intuito de demonstrar seu potencial valor 
Tabela 1

Sintese da teoria da aprendizagem experiencial

\begin{tabular}{|c|c|c|c|}
\hline Níveis de diferenciação & Aquisição & Especialização & Integração \\
\hline $\begin{array}{l}\text { Níveis de } \\
\text { profissionalidade }\end{array}$ & Ênfase na performance & Ênfase na aprendizagem & Ênfase no desenvolvimento \\
\hline Identidade profissional & "Penso em como faço" & $\begin{array}{l}\text { "Penso nos porquês do que } \\
\text { faço" }\end{array}$ & $\begin{array}{l}\text { "Penso em como melhorar o que } \\
\text { faço" }\end{array}$ \\
\hline Estrutura da consciência & Identificadora & Interpretativa & Integrativa \\
\hline Espaço ocupado na vida & $\begin{array}{l}\text { Respostas, atos, tarefas } \\
\text { Objetivos imediatos: para } \\
\text { alcançar metas }\end{array}$ & $\begin{array}{l}\text { Projetos, ocupações } \\
\text { Aprendendo como } \\
\text { aprender: para mudar } \\
\text { metas e estratégias }\end{array}$ & $\begin{array}{l}\text { Carreira, vida, gerações } \\
\text { Consciência integrada: para } \\
\text { vincular metas com uma } \\
\text { finalidade de vida }\end{array}$ \\
\hline Integração hierárquica & $\begin{array}{l}\text { Estruturas muito } \\
\text { diferenciadas com } \\
\text { baixa integração entre } \\
\text { elas }\end{array}$ & $\begin{array}{l}\text { Poucas estruturas, mas com } \\
\text { maior especialização. } \\
\text { Alta integração interna. } \\
\text { Baixa integração entre } \\
\text { estruturas }\end{array}$ & $\begin{array}{l}\text { Desenvolvimento de estruturas } \\
\text { especializadas e complementares } \\
\text { entre si. Desde baixa até alta } \\
\text { integração de estruturas }\end{array}$ \\
\hline $\begin{array}{l}\text { Experiência concreta e } \\
\text { complexidade afetiva } \\
\text { via apreensão }\end{array}$ & $\begin{array}{l}\text { 1 } \text { Sensações e } \\
\text { sentimentos primários } \\
\text { e instáveis } \\
\text { 2o Emergência de } \\
\text { sentimentos estáveis }\end{array}$ & $\begin{array}{l}\text { 1 } \text { Sistema egocêntrico de } \\
\text { sentimentos e valores } \\
2^{\circ} \text { Diferenciação entre } \\
\text { sentimentos e valores } \\
\text { próprios e os de outros }\end{array}$ & $\begin{array}{l}\text { 1 Apreciação relativizada de } \\
\text { sistemas de valores } \\
2^{\circ} \text { Compromisso com valores } \\
\text { relativizados (relativismo quanto } \\
\text { a valores assumidos) }\end{array}$ \\
\hline $\begin{array}{l}\text { Observação reflexiva } \\
\text { e complexidade } \\
\text { perceptiva } \\
\text { via intenção }\end{array}$ & $\begin{array}{l}\text { 1 Atenção } \\
2^{\circ} \text { Observação - imagens } \\
\text { contínuas }\end{array}$ & $\begin{array}{l}\text { 1 Reflexão: dar } \\
\text { significados pessoais às } \\
\text { observações } \\
2^{\circ} \text { Criação de esquemas } \\
\text { alternativos de } \\
\text { significação e de } \\
\text { observação }\end{array}$ & $\begin{array}{l}\text { 1 Apreciação relativizada } \\
\text { de esquemas diferentes de } \\
\text { significação e de pontos de vista } \\
2^{\circ} \text { Intenção; escolha de } \\
\text { perspectivas significativas }\end{array}$ \\
\hline $\begin{array}{l}\text { Conceituação abstrata } \\
\text { e complexidade } \\
\text { simbólica } \\
\text { via compreensão }\end{array}$ & $\begin{array}{l}1^{\circ} \text { Identificação e } \\
\text { reconhecimento } \\
2^{\circ} \text { Constância objetal }\end{array}$ & $\begin{array}{l}1^{\circ} \text { Operações simbólicas } \\
\text { concretas } \\
2^{\circ} \text { Pensamento formal, } \\
\text { hipotético dedutivo }\end{array}$ & $\begin{array}{l}\text { 1 Agregação de significados } \\
\text { concretos em sistemas } \\
\text { simbólicos } \\
2^{\circ} \text { Busca e resolução de problemas } \\
\text { significativos }\end{array}$ \\
\hline $\begin{array}{l}\text { Experimentação ativa } \\
\text { e complexidade } \\
\text { comportamental } \\
\text { via extensão }\end{array}$ & $\begin{array}{l}1^{\circ} \text { Resposta às } \\
\text { circunstâncias } \\
2^{\circ} \text { Ação intencional } \\
\text { em direção a metas } \\
\text { de curto alcance } \\
\text { (imediatas) }\end{array}$ & $\begin{array}{l}\text { 1ํ Desenvolvimento de } \\
\text { metas claras e de longo } \\
\text { alcance (prospectivas) } \\
2^{\circ} \text { Assumir riscos: } \\
\text { formulação de } \\
\text { metas e estratégias } \\
\text { intercambiáveis }\end{array}$ & $\begin{array}{l}\text { 1 Teste de hipóteses } \\
\text { experimentais: mudança de } \\
\text { metas e estratégias com base em } \\
\text { resultados obtidos } \\
2^{\circ} \text { Ação responsável: aceitação da } \\
\text { emergência de situações novas e } \\
\text { desconhecidas }\end{array}$ \\
\hline
\end{tabular}


para análises investigativas do desenvolvimento profissional. Esperamos, assim, ter contribuído para que se constitua um aporte a fundamentar pesquisas e programas na área.

\section{Referências}

Alarcão, I. (2002). Escola reflexiva e desenvolvimento institucional. Que novas funções supervisivas? In J. Oliveira-Formosinho (Org.), A supervisão na formação de professores (pp. 217-238). Porto: Porto Editora.

Beard, C., \& Wilson, J. P. (2002). The power of experiential learning. Londres: Kogan Page.

Burden, P. P. (1990). Teacher development. In W. R. Houston (Org.), Handbook of research on teacher education (pp. 311-328). Nova York: Macmillan.

Nóvoa, A. (Org.) (1992). Os professores e a sua formação. Lisboa: Dom Quixote.

Jarvis, P. (1995). Theory and practice. Londres: Routledge.
Kolb, D. (1984). Experiential learning. Englewood Cliffs, New Jersey: Prentice Hall.

Oliveira-Formosinho, J. (2002). O desenvolvimento profissional das educadoras de infância: entre os saberes e os afetos, entre a sala e o mundo. In M. L. de A. Machado (Org.), Encontros e desencontros em educação infantil (pp. 133-167). São Paulo: Cortez.

Pimenta, S. G. (2001). A pesquisa colaborativa na escola como abordagem facilitadora para o desenvolvimento profissional de professores. Relatório de pesquisa não-publicado, Universidade de São Paulo - FAPESP, São Paulo.

Sikula, J. (Org.). (1996). Handbook of research on teacher education. Nova York: Macmillan.

Vygotsky, L. S. (1987). Thinking and speech. In R. W. Rieber \& A. S. Carton (Orgs.), The collected works of L. S. Vygotsky (pp. 37-285). Nova York: Plenum.

Vygotsky, L. S. (1991). Obras escogidas (Tomo II - Conferencias sobre psicologia). Madri: Visor.

${ }^{1} \mathrm{O}$ presente artigo foi originalmente escrito como parte da tese de doutoramento Jogo e desenvolvimento profissional: análise de uma proposta de formação continuada de professores (2004), que contou com bolsa concedida pela FAPESP.

${ }^{2}$ David A. Kolb é professor de Comportamento Organizacional em Weatheread, EUA. Obteve o título de PhD por Harvard, em 1967. Nos Estados Unidos, o autor é uma referência para empresas e instituições educativas, além de ter disseminado o uso de seu Experiential Learning Slyle Inventory em pesquisas sobre desenvolvimento profissional.

${ }^{3}$ Em sua obra de maior projeção, Experiential learning (1984), Kolb se reporta com freqüência à perspectiva históricocultural de Vygotsky $(1987,1991)$.

${ }^{4}$ Diagrama adaptado do original, elaborado por Kolb (1984, p. 42).

${ }^{5}$ Kolb também formula combinações de três elementos (por exemplo, compreensão/apreensão transformadas por extensão), elegendo-as como formas superiores de aprendizagem e qualificando-as como típicas do nível integrado do desenvolvimento. Sobre esse tema, por exemplo, as análises críticas de Jarvis (1995) e de Beard e Wilson (2002) sugerem necessidade de maior aprofundamento da própria teoria kolbiana. Por esse motivo, este artigo se reporta somente às combinações elementares, dado que discutir as de nível integrativo foge do objetivo de uma apresentação geral sobre a aprendizagem experiencial.

Alessandra Pimentel, doutora em Educação pela Universidade de São Paulo, atualmente é professora substituta de Psicologia Educacional no Departamento de Educação da Universidade Federal do Rio Grande do Norte (UFRN). Endereço para correspondência: R. Ponta do Serrambi, 2241-B (Ponta Negra); Natal, RN; CEP 59092-170. Tel.: (84) 3236-2371, (84) 99453271. E-mail: alessandra@psicoeduca.com.br 